ISOCIRONOLS REIAXATIOX CLRYES FOR TYPE 304 STAIXLESS STEEL AFTER

the U S. Gowernment's raght eo

rolle 7 a noneuglusive, novalty trate

incense in and to any copyright

covering the entecife.

\title{
MONOTONIC AMD CICIIC STRAIS*
}

R. W. Sw indeman

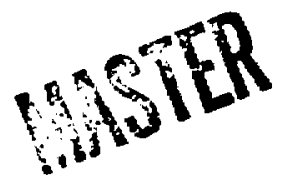

Metals and Ceramics Diyision

Oak Ridge National Laboratory

Oak Kidge, Tennessee 37830

\begin{abstract}
ABSTR:CT
Relaxation tests to $100 \mathrm{hr}$ were performed on type 304 stainless steel in the temperature range 480 to $650^{\circ} \mathrm{C}$ and were used to develop isochronous relaxation curves. Behavior after monotonic and cyclic strain was compared. Relaxation differed only slightly as a consequence of the type of previous strain, provided that plastic flow preceded the relaxation period. We observed that the short-tine relaxation behavior did not manifest strong heat-to-heat variation in creep strength.
\end{abstract}

*Research sponsored by the U.S. Department of Energy under contract W-7405-eng-26 with the Union Carbide Corporation. 


\section{INTRODUCT:ON:}

Type 304 stainless steel is widely used as a structural material in fossil and nuclear power plants. The high thermal expansion coefficient, low thernal conductivity, and low yield strength of type 304 stainless steel, make it susceptible to thermal siresses wich exceed its y ield strength. At temperatures below $427^{\circ} \mathrm{C}\left(800^{\circ} \mathrm{F}\right)$, Section III of the ASME Boiler and Pressure Vessel Code provides criteria to protect structures from low-cycle fatigue and excessive ratchetting. Simplified elastic design methods are available for most applications, and relaxation data are not needed. Above $427^{\circ} \mathrm{C}$ relaxation of residual stresses by thernal creep is assumed possible. This relaxation produces creep strains which damage the material. For cyclic situations the ASiE Code Case 1592 provides design criteria to protect structures from failure by creep-fatigue ratchetting mechanisms. 1 The designer has the option to perform a simple elastic analysis and use very conservative design limits or perform a more sophisticated inelastic analysis. If he chooses the latter option, the designer is allowed more generous design limits. ${ }^{2}$ The ASME Code provides materials data which the designer can use to solve some problems requiring inelastic analyses. Isochronous stress-strain curves, ${ }^{3}$ for example, are 
quite useful for problems shich involve monotonic creep. However, no data are available for quick estimates of residual strosses when inelascic strain accumulates under relaxation conditions. For such problems isochronous relaxation curves, if they can be developed, could prove considerably valuable. The concept of isochronous relaxation curves is not a new one. Curves for $1 / 2 \mathrm{Cr}-\mathrm{Mo}-\mathrm{V}$ steel were presented by Elder, Marriott, and surphy in $1972^{4}$ and for $21 / 4 \mathrm{Cr}-1$ : to steel by Ellis et al in $1975 .^{5}$ This report summarizes work on the subject at the Dak Ridge National Laburatory. Most data have been accumulated on a single heat of type 304 stainless steel used in a program sponsored by the Department of Energy. This program intends to develop high-temperature structural design methods and failure criteria. MATER IAL AND TEST :IETHODS

Specimens were machined from a $25 \mathrm{~mm}$ plate of a reference heat of material ${ }^{6}$ (heat 9 T2796) with the following ladle analysis: $0.048 \% \mathrm{C}$, $1.22 \% \mathrm{Mn}, 0.028 \% \mathrm{P}, 0.015 \% \mathrm{~S}, 0.048 \% \mathrm{Si}, 18.6 \% \mathrm{Ni}, 9.7 \% \mathrm{Cr}$, and $0.32 \%$ \%o. Most specimens were threaded-end bars with $6.35 \mathrm{~mm}$ gage section diameters. After machining specimens were reannealed for $0.5 \mathrm{hr}$ at $1093^{\circ} \mathrm{C}$ in argon and rapidly cooled. In this condition the material had a $120 \mathrm{\mu m}$ average grain size, a Diamond Pyramid Hardness valu. near 125, and a room temperature yield near $176 \mathrm{MPa}$.

Montonic tests were performed in the system shown schematically in Fig. 1. The specimen was placed in 44-kN electrohydraulic testing machine and heated in a resistance furnace. Temperatures were maintained to within $\pm 2^{\circ} \mathrm{C}$ 
of the reported temperature throughout the tast. For low stress tests, in which strains were small, an extensometer was attached to the center 25 of the reduced section. For high-stress tests, when strains exceeded $1 \%$, the extensometer was attached to the shoulders. This produced an effective elastic gage length near $38 \mathrm{~mm}$. The creep strain gage length was near $32 \mathrm{~mm}$. The extensometer was an averaging type with Linear Variable Differential Transducers. The sensitivity was better than $\pm 10 \times 10^{-6}$ strain. All tests were performed in a servo-controlled mode using the extensometer feedback signal for control. Control was better than $\pm 25 \times 10^{-6}$ strain, although in several instances command signal Eluctuations produced changes in the control strain, which exceeded $25 \times 10^{-6}$ strain in the specimen.

Cyclic tests were performed in a system shown schematically in Fig. 2. Here the $s_{i}$ ecimen was placed in a die-set gripping fixture mounted in a $110 \mathrm{kX}$ electrohydraulic testing system. The specimen was heated by induction. Temperatures were maintained constant within $\pm 2^{\circ} \mathrm{C}$ of the reported value. The extensometer was attached to one side of the specimen and had a sensitivity near $10 \times 10^{-6}$ strain. Straj ; were controlled within $\pm 25 \times 10^{-6}$ strain.

\section{RESULTS}

Relaxation curves for a series of tests at different temperatures are compared in Fig. 3. All tests were started at nearly the same stress (approximately $210 \mathrm{MPa}$ ) and strain (approximately 7-9\%), but the temperatures ranged from 482 to $649^{\circ} \mathrm{C}$. Most of the relaxation occurred during the first ten hours of testing. Relaxation, however, increased dramatically as the temperature increased from 482 to $649^{\circ} \mathrm{C}$. This, of course, implies that thermal activation is very important to the relaxation process in this temperature range. Another series of tests at different initial stresses are compared in $\mathrm{Fig}$. 4. All tests were at $538^{\circ} \mathrm{C}$, but the starting stresses ranged from near 80 to $275 \mathrm{MPa}$ with corresponding starting strains fron 0.5 
to 15\%. Tests with high starting stresses exhiblted high inftial relaxation rates. However, the curves converge very little after ten hours or so, possibly because of differences in the "hardness" of the material ${ }^{7}$ produned by the different plastic loading strains. Alternatively, tests with bigh starting stresses may have absorbed more creep strain while relazing to a given stress and this creep strain produced creep hardening, manifested by low relaxation rates at lower stresses.

Isochronous relaxation curves conveniently represent the influence of the previous plastic strain on the relaxation response. Such curves are shown in Fig. 5 for the relaxation data at $538^{\circ} \mathrm{C}$. To construct the curves the engineering stress data shown in Fig. 4 were converted to true stresses for $0,1,10$, and $100 \mathrm{hr}$ and plotted against true strain. The strain for each test was chosen so that the starting relaxation stress fell on a "reference" stress-strain curve (labelled $0 \mathrm{hr}$ ), which represented a monotonic tensile test at a strain rate near $6.7 \times 10^{-5} / \mathrm{s}$. The relaxation strength clearly rises systematically with strain and the slope of each isochronous curve either equals or falls below that of the stress-strain curve. The slope decreases with increasing time or initial stress.

Isochronous curves for $482,566,593$, and $649^{\circ} \mathrm{C}$ are shown in Figs. 6-9, respectively. As the temperature increases, relaxation increases, and the slope of the isochronous curve decreases. These isochronous relaxation curves complement the isochronous stress-strain curves derived from tensile tests and constant load creep data, and developed for use in design by Manjoine. 8 The isochronous relaxation curves differ in several ways from the isochronous stress-strain curves. The most fundamental difference, of course, is that the isochronous stress-strain curves apply to load-controlled situations, whereas the isochronous relaxation curves apply to strain-controlled situations. For a given time and strain the curves also 
differ in indicated stress level. As an example, In Fig. 5 the 100-hr I sochronous curve based on creep data at $538^{\circ} \mathrm{C}$ can be compared to a curve based on relaxation data at the same temperature and time. The isochronous relaxation curve produces stresses substantially below the isochronous stress-strain curve, especially at high strains. Another feature unique to the isochronous relaxation curve is its relative insensftivity to heat-to-heat variations, at least for short-time applications. As an example, the relaxation strengths at 1,10 , and $100 \mathrm{hr}$ for several heats are compared -. in Fig. 10 ta. the strengths predicted from the isochronous curves deyeloped . for heat 9T2796. Data sources include a compilation by Freeman and Voorhees $^{9}$ (ASTM STP 187), Manjoine, ${ }^{10}$ and work at ORNL. 11 Most of the data fall within $\pm 10 \%$ of the predictions. This scatter is small compared to the $\pm 20 \%$ or more typical of the variation in creep strength from heat to heat. 12

Isochronous relaxation curves also differ from isoct ronous creep curves in treatment of response after cyclic strains. No proven way exists to use the isochronous stress-strain curve to predict the relaxation of stress after a reversed plastic strain transient. However, such a prediction may easily be made from isochronous relaxation curves if one knows the peak stress in hysteresis loop. A nethod is shown schematically in Fig. 11. Here a hysteresis loop is centered about zero strain. The peak stress, $\sigma_{\text {maxis }}$ is translated parallel to the abscissa of the plot to the intersection with the zero time isochronous relaxation curve. The relaxed stress, $\sigma_{R}$, can then be estimated by reading downward from this point to the approprial : isochronous relaxation curve for the hold period in the cycle. This method assur as that the relaxation curve for any hold perlod during repetitive strain-cycling is the same as the relaxation curve for the monotonic test. Data which support the validity of this assumption are shown in Figs. 12 and 13 . Figure 12 shows data obtained from relaxation rests on cycled specimens of heat 9 T2796 at $593^{\circ} \mathrm{C}$. The relaxation strengths for 1,10 , and $100 \mathrm{hr}$ are plosted against the 
strain values characteristic of the monotonic tests for che sanc starting stress. Data show that cycling generally produces slightly lower st rengths than do the monotonic tests, but the overall trend is similar. Figure 13 compares the relaxation strengths produced in cyclic tests on a number of heats to relaxation strengths predicted from monotonic tests on a single heat (9T2796). Data sources include Ma jumbar and :laiya, 13 Conway et al., ${ }^{14}$ Iida, ${ }^{15}$ and ORiL work. 11 in general the obscrved relaxation strengths fall within 90 to $100 \%$ of the predicted strengths. The ubserved and predicted values agree well, considering that heat-to-heat .... -scatter in creê" strength for type 304 stainless steel is about $\pm 20 \%$.

Although the isochronous relaxation curves shown in this report represent both monotonic and cyclic loadings, they do not apply in a number of situations.

1. We know that very short-tine relaxation behavior, say for the first ten minutes or so, is influenced by the plastic strain rate preceding the relaxation hold. 11,12 This is shown schematically in Fig. 14. The lower plastic strair rates often produce lower relaxation rates even though the strain rate may not greatly affect stress-strain behavior. The isochronous curves shown in this paper generally reflect behavior of material strained at a rate near $6.7 \times 10^{-5} / \mathrm{s}$. Some of the cyclic data, however, reflect the behavior of material strained at rates as high as $4.3 \times 10^{-3} / \mathrm{s}$. Strain-rate differences may explain why short-time cyclic strengths fall below predictions based on monotonic data.

2. We have evidence that for reloading conditions which do not produce plastic strain before relaxation (1.e., elastic reloading), the relaxation rate decreases from one run to the next. Since the isochronous relaxation curves sere constructed from test data from runs in which some plastic strain 
had been introduced before each loading, the predicted relaxation may be greater than observed in situations in which only elastic reloading occurred.

3. The response in the stress transient "dip test" is not captured. In this loading condition, similar to that of the experiments of Solozon, 16 plastic or creep strain is introduced at a high stress and the relaration response is observed after a rapid load decrease. The behavior for this loading condition is shown schematically in Fig. 15 for several unloading increments. Generally, the short-time response shows less relaxation than predicted from isochronous relaxation curves. At some stress levels, in iact, the stress remains constant or even increases for a period which can last zany hours. This, of course, rerilects the influence of the "back stress" often associated with dislocation pile-ups or dislocation bowing and is related to the internal stress. 17

\section{DISCUSSION}

In this report we have emphasized the features of an experimentally developed set of isochronous relaxation curves. These curves may be used in much the same way as the isochronous stress-strain curves now contained in the ASYE Boiler and Pressure Vessel Code. However, we do not suggest that the isochronous relaxation curves substitute for properly formulated constitutive relationships and proper materials data. In fact, if the proper constitutive relationships are established, we should be able to predict relaxation behavior even if many of the complex histories for which the isochronous relaxation curves were developed do no: apply. In this regard, a significant effort is underway in the U. S. and elsewhere to develop and verify unified constitutive equations, which can represent materiai behavior over a broad range of conditions. Examples are the work of Hart, 18 Onat, ${ }^{19}$ Niller, ${ }^{20}$ Swearengen and Rhode, ${ }^{21}$ and Gittus, ${ }^{22}$ to 
mention just a faw. Yany of these efforts center on the descriation of the creep rate as a function of stress, temperature, and one or more structure-dependent state vartables. The determination of creep curves and relaxation curves from these models often regaires the solution of two or more coupled differential equations which relate to flow rules and growth laws.

The data we report here have been processed into the type of information needed for constitutive equation development, for example, temperature, history, and strain rate as a function of stress. Results ara currently being used to guide the deveiopment of constitutive equations needed for the U.S. breeder reactor program. We refer to the work of Robinson, Pugh, and Corum $^{23,24}$ for more details. The scope of this paper, however, does not include a discussion of the implications of our data for constitutive equation development.

We do feel, however, that this paper should consider the use of isochronous relaxation curves to analyze creep-fatigue behavior. The bulk of the data on creep-fatigue are derived from tests which involve strain-controlled constant strain-rate cycling with relaxation hold periods at the hysteresis loop tips. Hold times are in the range 0.01 to $1 \mathrm{hr}$. Very few data are available for hold times beyond $\mathrm{l}$ hr. For design applications a need exists to predict relaxation for times in the range 10 to $1000 \mathrm{hr}$. From such data the creep "damage" is estimated and used to develop the conservative strain-fatigue cu'ves needed for simplified elastic analyses. $^{25}$ Many investigators correlate their short-time relaxation data by means of an equation developed by Gittus ${ }^{26}$ and later modified by Conway. 27 Examples may be seen in the work of Jaske and co-workers, 28 If da and co-workers, ${ }^{15}$ Ma juubar and Malya, ${ }^{13}$ and Bui-Quoc et al. 29 Gitcus developed his equation from a creep law of the form:

$$
\dot{e}=A \sigma^{n} t^{m}
$$


where $c$ is creep rate, $\sigma$ is stress, $t$ is time, and $A, r$, and $m$ are material parameters which depend on temperature. Gittus showed that the relaxation behavior of Nimonic $80 \mathrm{~A}$ springs could be best modelled by assuming that creep rate is 1 inear with stress. That $1 s$, the stress exponent, $n$, is near unity. The original Gittus equation for relaxation was then developed into the form:

$$
\frac{C_{0}}{\sigma}=\operatorname{ext}\left(\because E^{m+1}\right)
$$

Conway modified the equation by eliminating the starting stress and arrived at the equation:

$$
\left|\frac{\dot{\sigma}}{\sigma}\right|=\frac{M E t^{m}}{n_{t}+1}
$$

which plots linearly on $\log -\log$ coordinates. Equation ( 3 ) can be easily integrated to produce either a relaxation curve or a measure of damage during the relaxation process. We have examined our data in terms of Eq. (3) and show some examples in Fig. 16. Generally we find that the equation provides a reasonably good fit. However, we point out that the equation assumes a stress exponent of unity, whereas if the relaxation results from dislocation creep or glide we would expect an exponential or power law $(n>1)$ dependency. If the Gittus-Conway model really applies, then we can only conclude that anelasticity, or some similar phenomenon, must play an important role in the relaxation process. of course, other deformation processes, such as diffusion creep, also have a stress exponent of unity, but we think that the creep rates associated with these processes are too low to consider here. We expect that power law creep will eventually dominate the relaxation process, hence to extend Eq. (3) out of the range of available data is sonewhat tenuous.

Relaxation behavior may also be predicted by the straightforward use of a creep law in conjunction with the-hardening or strain-hardening theory. Above $650^{\circ} \mathrm{C}$ power 1 aw creep in conjunction with time-hardening provides a good method to predict relaxation for type 304 stainless steel. This has been shown by Kennedy ${ }^{30}$ and Manson and Zab. 31 At $600^{\circ} \mathrm{C}$ and below, strain-hardening guides 
relaxation predictions reasonably weil for low starting stresses and for a single relaxation period. This has been shown by Pugh. 24 However, the fact that reloading into the plastic range, or reversal loading, produces relaxation behavior which differs little from relaxation behavior in the first loading implies that strain-hardening has only limited value in predicting relaxation behavior. We assume that behavior in cyclic relayation reflects the influence of either anelasticity or dynamic recovery process.

The experimental isochronous relaxation curves constructed here nake no assumptions about the deformation mechanisms or hardening laws and seea to apply, piovided some plasticity precedes relaxation. We must point out, however, that the experimental data are limited to total testing times in the range 1 to $1000 \mathrm{hr}$. No one really knows whether the material will behave similarly in the 10,000 to $1000,000-h r$ range. Yore sork in this testing regime is necessary.

\section{CONCLES IONS}

1. In the temperature range 480 to $650^{\circ} \mathrm{C}$ isochronous relaxation curves can be constructed from relaxation data by plotting the true stress versus the true strain. The strain is determined by locating the starting stress of the relaxation test on a reference stress-strain diagram established at high strain rates.

2. Isochronous relaxation curves should apply to strain-controlled situations while isochronous stress-strain diagrams should apply to stress-controlled conditions. Isochronous relaxation curves reflect lower stresses than do isochronous stress-strain curves at equivalent times.

3. Isochronous relaxation curves show less heat-to-heat variation than do isochronous stress-strain curves. 
4. Isochronous relaxation curves may be used to approzizately predict relaxation in cyclic-strain situations in which hold timis are introduced at peak strains.

5. The use of isochronous relaxation curves should be limited to relatively short times, less than $1000 \mathrm{hr}$, and to situations in sich relaxation is preceded by macroscopic plastic flos.

\section{ACRNOKLEDGHENTS}

The author is indebted to $\mathrm{K}$. C. Williams sho performed all of the mechanical tests. D. X. Robinson, K. C. Liu, and C. R. Briniman reviesed the paper and provided some heipful suggestions. The paper was prepared by K. A. Witherspoon and edited by $\mathrm{N}$. Kichards.

\section{REFERENCES}

1. "Class 1 Components in Elevated Tamperature Services, Class III,"

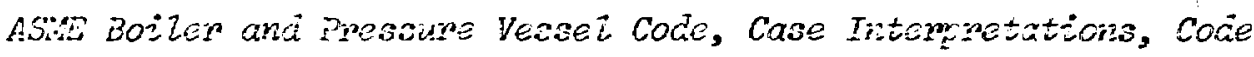
Case 1592, American Society of Mechanical Engineers, New York.

2. L. K. Severud, "Elevated Temperature Fatigue-Design-spplication Perspective with Directions for Improvement," pp. 41-5j in $37 \hat{\imath}$ AS:E-APC Simposium on CrEep-Fatijue Interaction, ed. by R. H. Curran, American Society of Mechaniral Engineers, New York, 1976.

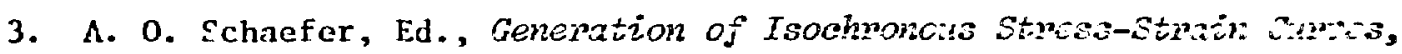
American Society of Mechanical Engineers, New York, 1972.

4. W. J. Elder, J. B. Marriott, and M. C. Murphy, "High-Strain Fatigue Properties of Case $1 / 2$ Cr-Mo-V Steels," pp. 320-31 in Fit: inte cit Elevated Temperatures, Am. Soc. Test. :ater. Sreu. Foch. Pub. 5:0, American Society for Testing and Materials, Philadelphia, 1973. 5. J. R. Ellis et al., "Elevated Temperature Fatigue and Creup-Fatigue Properties of Annealed $21 / 4 \mathrm{Cr}-1$ Mo Stecl," pp. 213-46 in Stracesura 


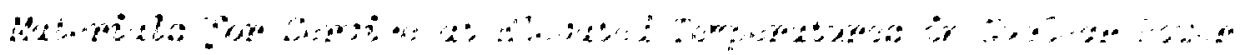

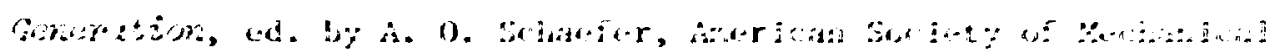

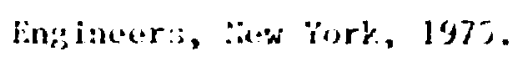

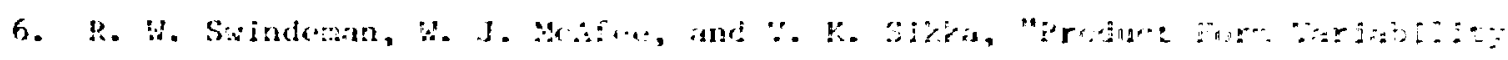

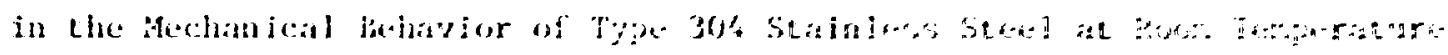

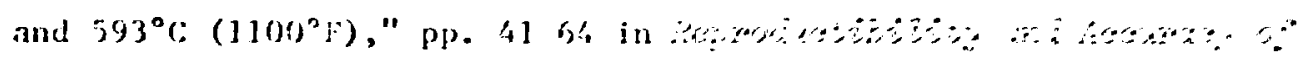

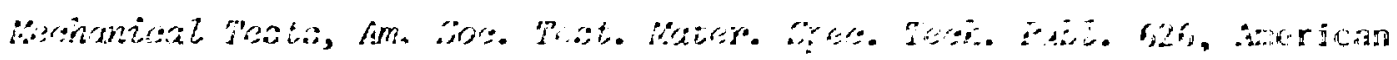

Society for lesting and Haterjals, Philadelpinia, 1977.

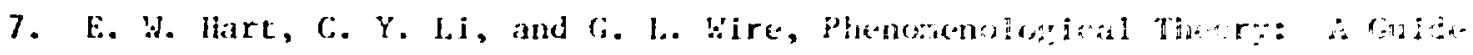

to Constitutive Relations and fundamental deforazt:an properties,"

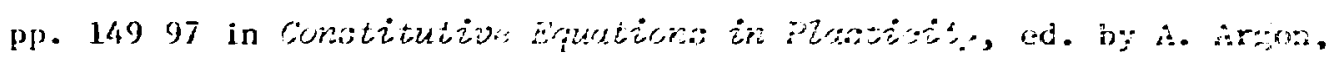

HIT Press, Cambridge, Massachusetts, 1976.

8. M. J. Manjoine, "Isochronous Stress-Strain Curves of Type 304 Staindess stee1," iet. ing. 2. 2: 31-33 (1971).

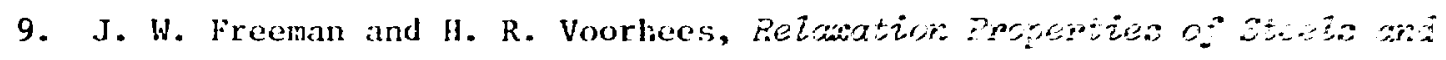

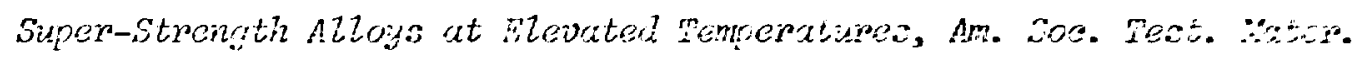
Spec. Tech. Pubz. 187, American Society for Testing; and Materials, Philadelphia, 1956.

10. M. J. Manjoine, "Stress Relaxation Characteristics of Type 304 Stainless

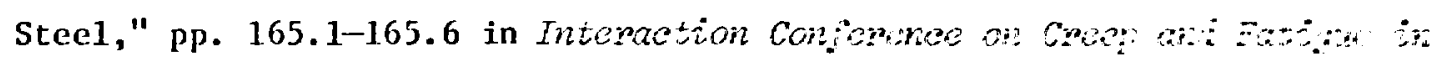
EZevated Temperature Applications, institute of Mechanical Emsineers, London, 1974.

11. Unpublished work at the Oak Ridge National Laboratory.

12. V. K. Sikka et al., "Heat-to-lleat Variation in Creep Properties of

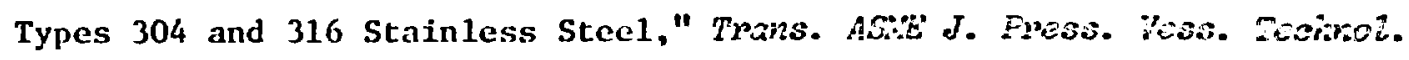
97: $243-51(1975)$. 


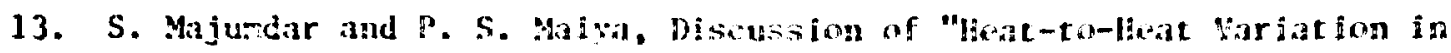
Creep Propertius of Types 304 and 316 stainiass Stee:" to be prablished

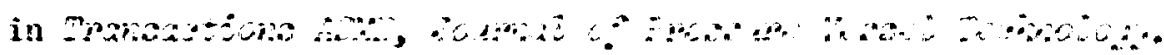

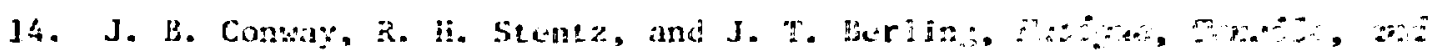

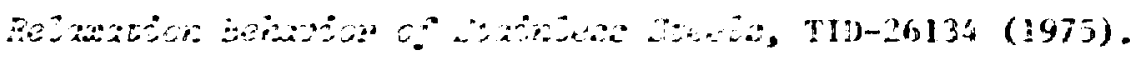

15. K. Iida et al., Fen and

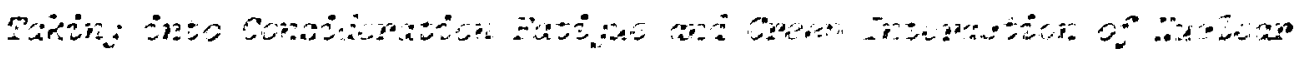

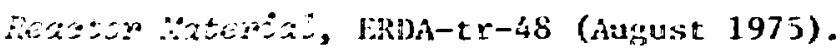

16. A. 3. Solomon, "ews Technique and Apparate; for Examining the Clevated

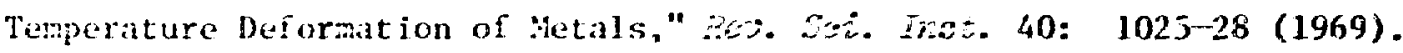

17. C. $\because$. Anlquist and $\because .0$. $N i x$, " $A$ Technique for Measuring Yean Internal

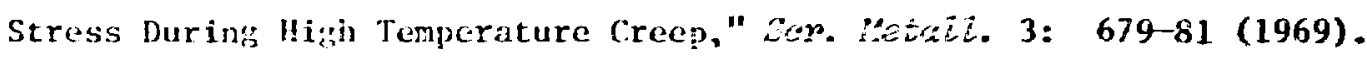

18. E. W. Hart, "Constitutive Relations for the Nonelastic Deforination of

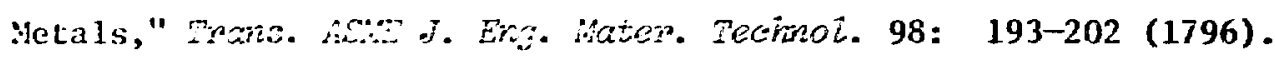

19. E. T. Onat and $\mathrm{r}$. Fardshisheh, Rep pesentatich of cheep of Hetais, ORVL-4783 (August 1972).

20. A. K. Ailler, "An Inelastic Constitutive Model for Monotonic, Cyclic, and Creep Deformation, Part I. Equations Development and Anilytical procedures," Trans. ASHE J. Erg. Mater. TecinzoL. 98: 97-113 (1976).

21. R. W. Rhode and J. C. Shearengen, "A Mechanical Equation of State for Inelastic Deformation of Iron: An Analytical Description," to be publ ished in Acta Aetalzurgica.

22. J. Gittus, "The Mechanical Equation of State: Dislocation Creep Due to Stresses Varying in Magnitude and Direction," Pisizos. Aag. 24: $1423-40(1971)$.

23. D. N. P.obinson, C. E. Pugh, and J. M. Corum, "Constitutive Equations for Describing High-Temperature Inelastic Behivior of Structural Alloys," 


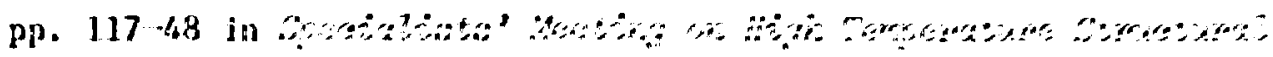

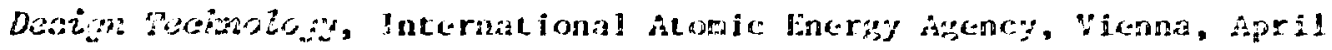
1976.

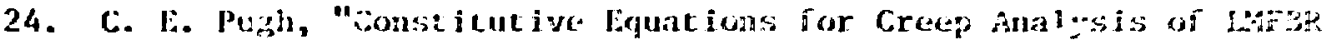

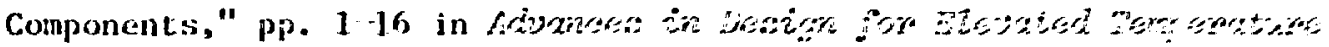
Envircument, ed. by S. Y. Zanrit: and R. 1. Jetter, American Soxictz of Mfecinanical fingincers, very rork, 1975.

25. R. D. Campbell, "Creep-Fatigue Interaction Correlation for 304 Stainless Steel Subjected to Strain-Controlled Cycling with Hold Times at Pear. Strain," Trons. Aä, J. Hig. Ina. 93: 887-92 (1971).

26. J. H. Gittus, "Implications of Sone Data on Relaration Creep in Misonic 80A," Philos. Mas. 9: $749-53$ (1964).

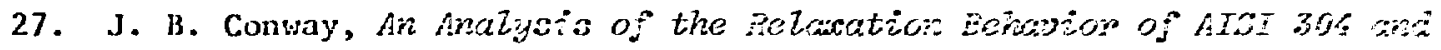
310 Stainless sicel at Elevated Tumeratmes, GHP-730 (1969).

28. C. E. Jaske, H. Mindlin, and J. S. Perrin, "Combined Iow-Cycle Fatiguc and Stress Relaxation of Alloy 800 and Type 304 Stainless Sterl at

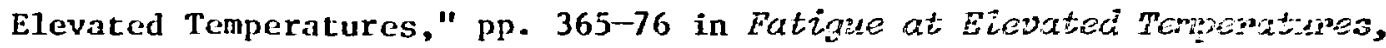
Am. Soc. Test. Kater. Spec. Tech. Pubz. 520, American Society for Testing and Materials, Philadelphia, 1973.

29. T. Bui-Quoc, R. E. Sahcb, and A. Biron, "Evaluation of Hold-Time Effect in Fatigue at Elevated Temperature on a Stainless Steel," ASxE paper 75-WA/PVP-17, presented at ASNE Annual Meeting, Winter, 1975.

30. C. R. Kennedy, unpublished work in support of the Experimental Gas-Cooled Reactor Program, Oak Ridge National Laboratory, 1962.

31. S. S. Manson and R. Zab, Treatment of Low Strains asa Lont Hozi Tires in High Temperature Hetal Eatigue bis Strain Ranie Partitioning, Mechanical Aerospace Engineering, Case Western Reserve University, ORNL/Sub-3988/1 (August 1977). 


\section{ST OF FIGLRES}

Fig. 1. Schematic : ..perimental Setup for Monotonic Relaxarion Testing.

Fig. 2. Schematic of Experimenta! Setu; for Cuclic Relazation Testing.

Fig. 3. Comparison of kelaxation Curyes for Tye 304 Stainless Steel at 482, 538, 593, and $649^{\circ} \mathrm{C}$. The starting stress is near 210 MPa for all tests.

Fig. 4. Comparison of Relayation Curves for Type 304 Stainless Steel at Several starting Stresses. Temperature is $538^{\circ} \mathrm{C}$.

Fig. 5. Isochronous Relaration Curves for Type 304 Stainless Stee1 at $538^{\circ} \mathrm{C}$.

Fig. 6. Isochronous Relaxation Cur es for Type 304 Stainless Steel at $482^{\circ} \mathrm{C}$.

Fig. 7. Isochronous Relazation Curves for Type 304 Stainles. Steel at $566^{\circ} \mathrm{C}$.

Fig. 8. Isochronous Relaxation Curves for Type 304 Stainless Steel at $593^{\circ} \mathrm{C}$.

Fig. 9. Isochronous Relaxation Curves for Type 304 Stainless Steel at $649^{\circ} \mathrm{C}$.

Fig. 10. Comparison of the Relaxation Strength at 1,10 , and 100 hr for Three Heats of Type 304 Stainless Steel with the Strength Predicted by the Isochronous Rela:ation Curves Developed from a Single Heat.

Fig. 11. Method of Estimating the Relaxation Component of a Cyclic Test from Isochronous Relaxation Curves. Stress ( $\sigma) ; \operatorname{strain}(\varepsilon)$.

Fig. 12. Comparison of Relaxation Data from Cyclic Tests with Isochronous Relaxation Curves Developed from Monotonic Tests at $593^{\circ} \mathrm{C}$. Strain ranges from near $0.4 \%$ to $2.0 \%$ 
Fig. 13. Comparison of the Cyclic Melazazion: Strength for Five tieats of Type 304 Stainless Steel with the Strength Predicted by the Isochronous Relazation Curves Developed fros Sonotonic Tests on a Single Heat. Hold tire for heats $346845,346544,822807$ is 1 hr. hold times for heat 8043813 are 1, 10, and $100 \mathrm{hr}$. Hold times for heat 55697 are 1 and 10 hr.

Fig. 14. Influence of Ramp Strain Rate on Relazation of Type 304 Stainless Steel at $593^{\circ} \mathrm{C}$ and $0.58 \%$ Strain Range.

Fig. 15. Relaxation Curves Produced by Rapidly Reducing the Starting Stress, $\sigma_{0}$, to Various Fractions of the Flow Stress, $\sigma_{z}$. Type 304 Stainless steel at $649^{\circ} \mathrm{C}$.

Fig. 16. Relaxation Data for Type 304 Stainless Steel Plotted by the Conway Method. 


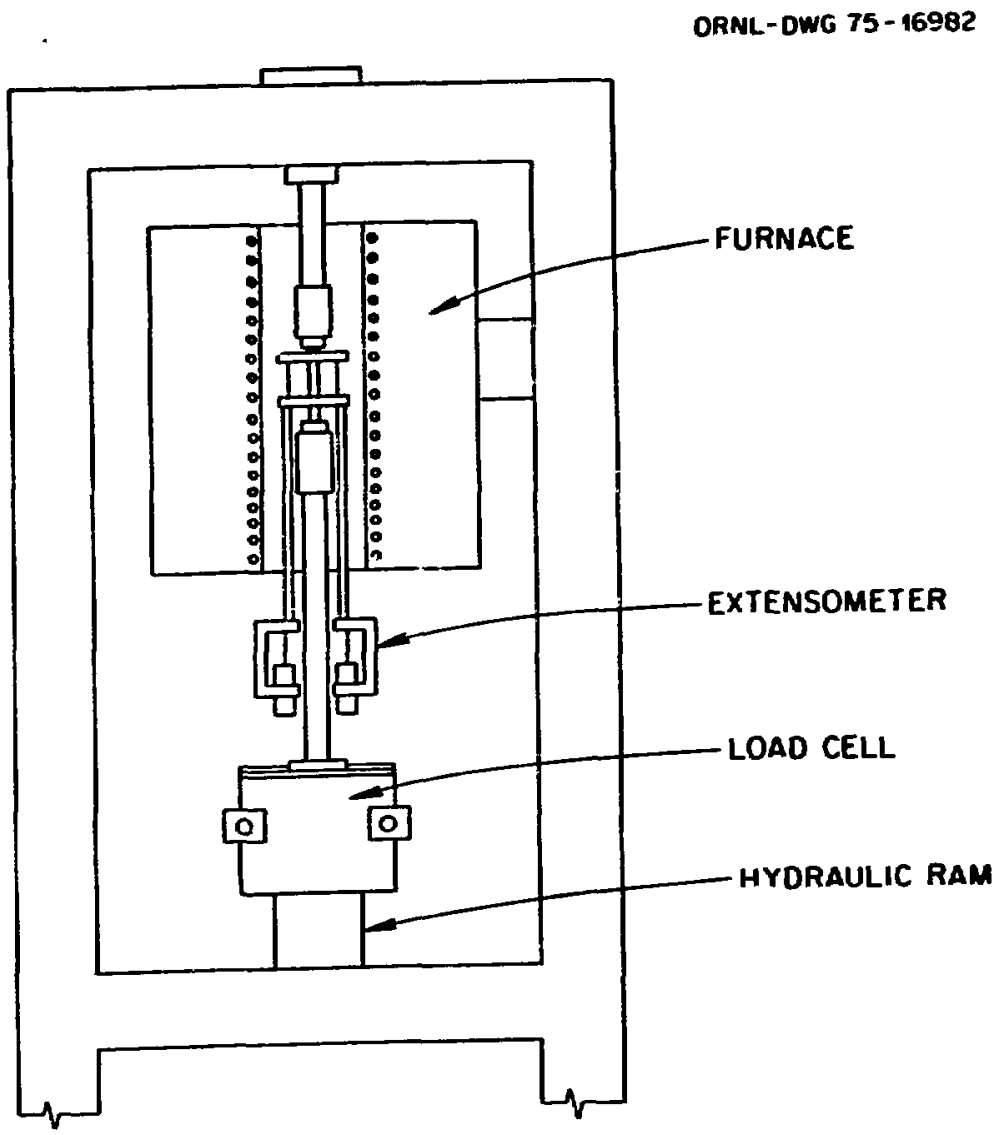

1

Fig. 1. Schematic of Fxperinental Setup for Monotonic Relaxation Testing: 
ORNL-DWG 76-19718

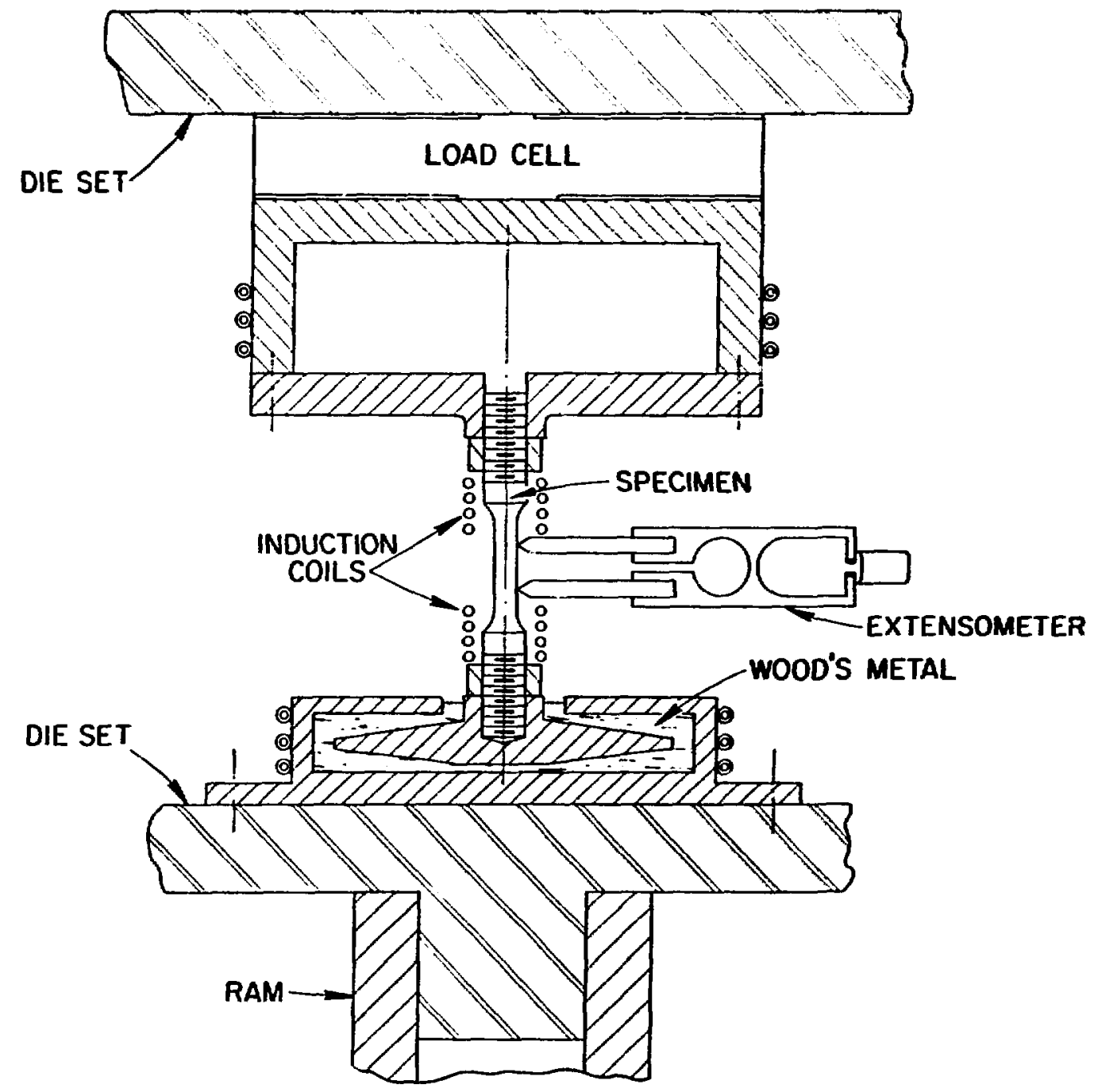

Fig. 2. Schematic of Expcrimental Setup for Cyclic Rolaxation Testing;- 


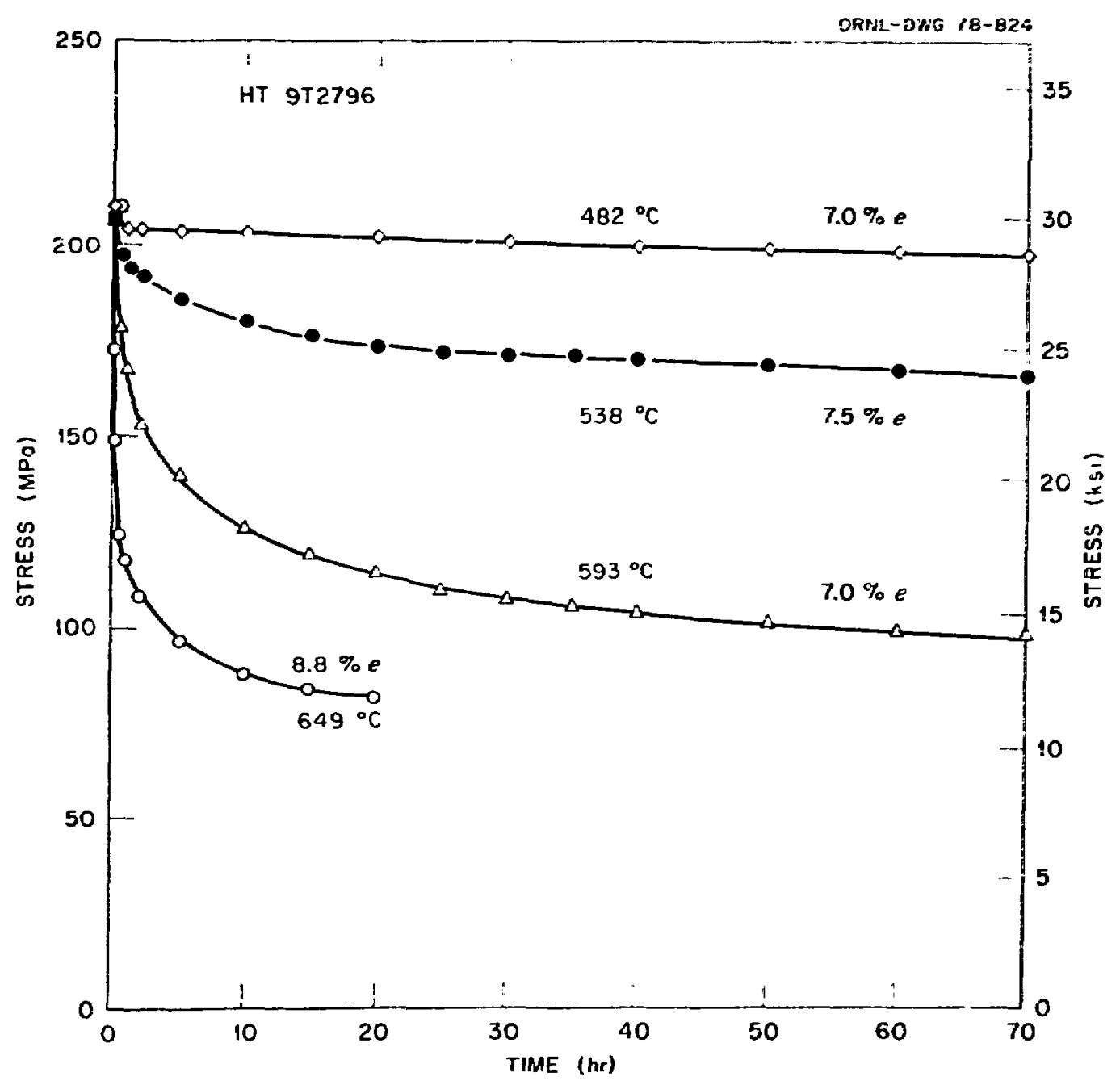

Fig. 3. Comparison of Relaxation Curves for Type 304 Stainless Stcel at 482, 538, 593, and $649^{\circ} \mathrm{C}$. The searting stress is near $210 \mathrm{MPa}$ for al1 tests. 


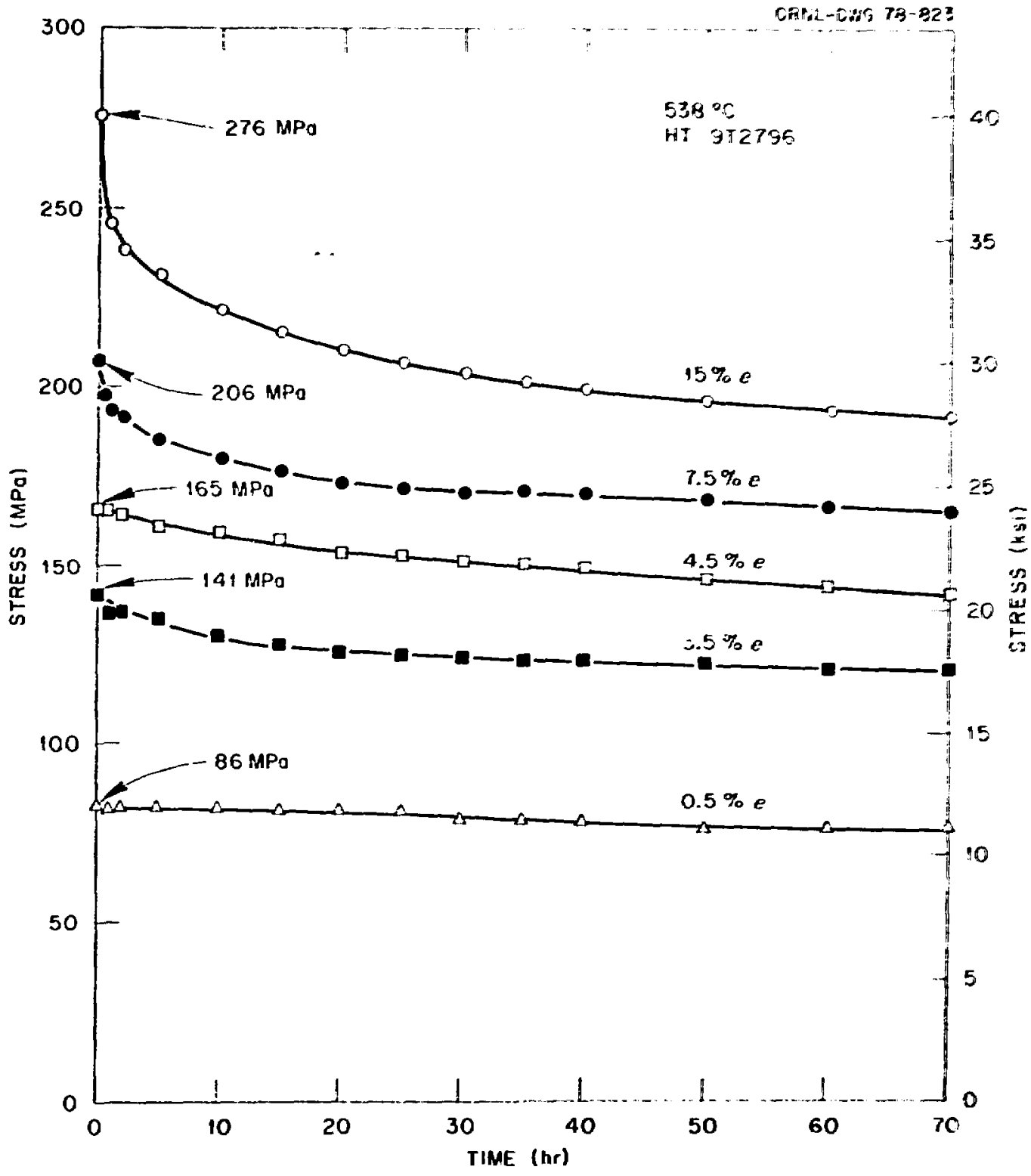

Fig. 4. Comparison of Relaxation Curves for Type 304 Stainless Steal at Several stateting strusses. Tenperature is $330^{\circ} \mathrm{C}$. 


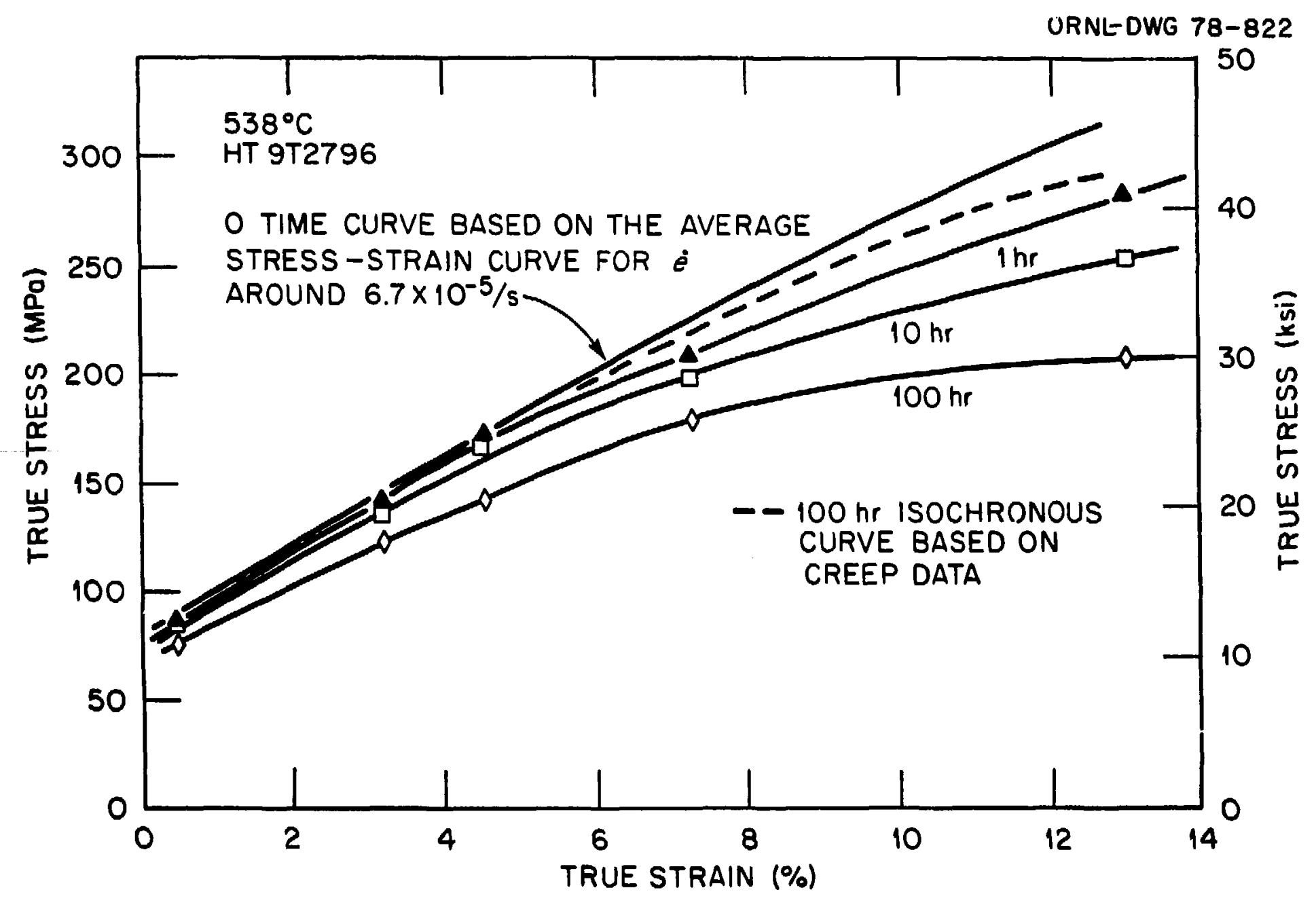

Fig. 5. 1sochronous Relaxation Curves for type 304 Stalnless sted at $538^{\circ} \mathrm{C}$. 


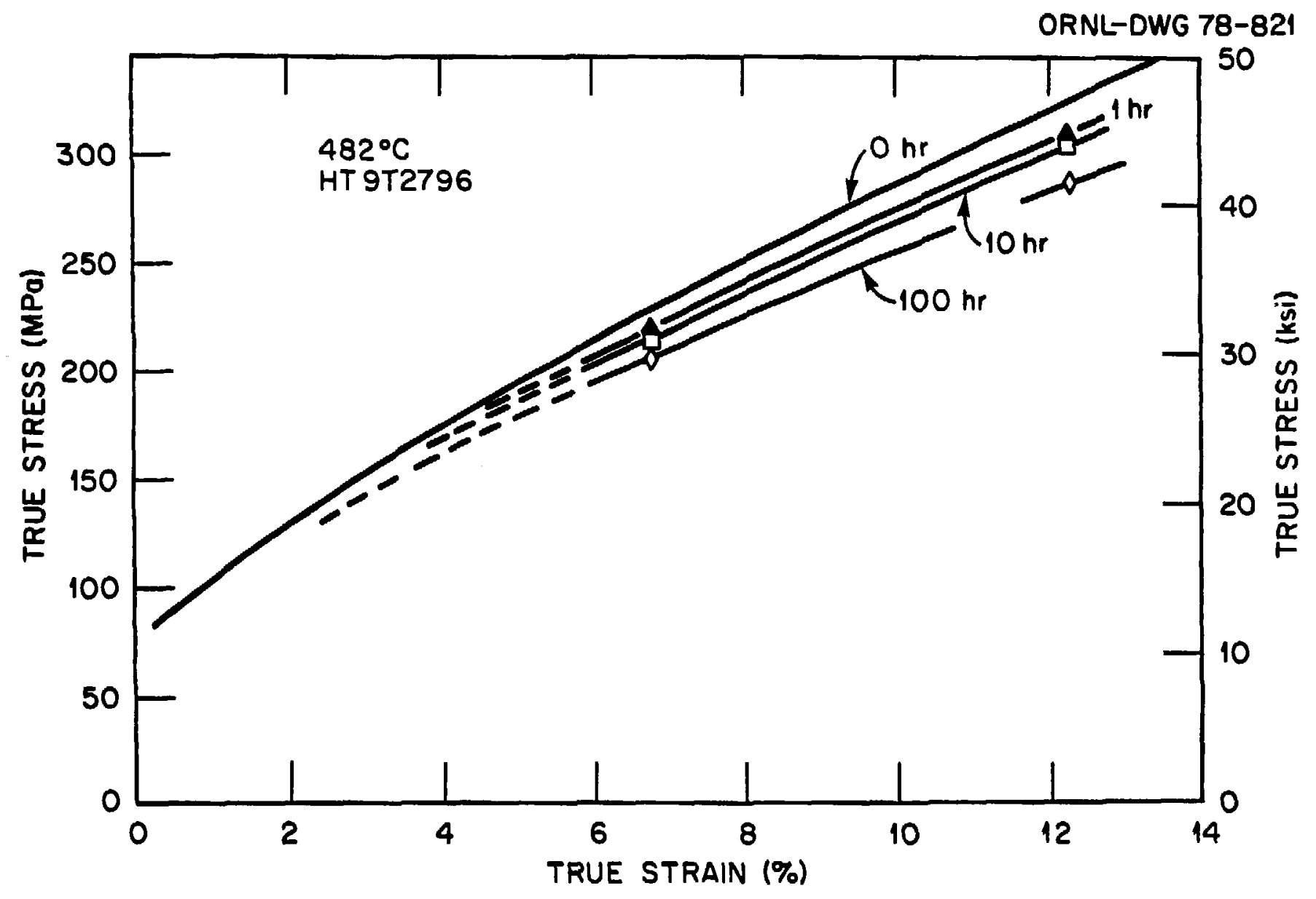

Fig. 6. Isochronous Relaxation Curves for Type 304 stainluss sted at $482^{\circ} \mathrm{C}$. 


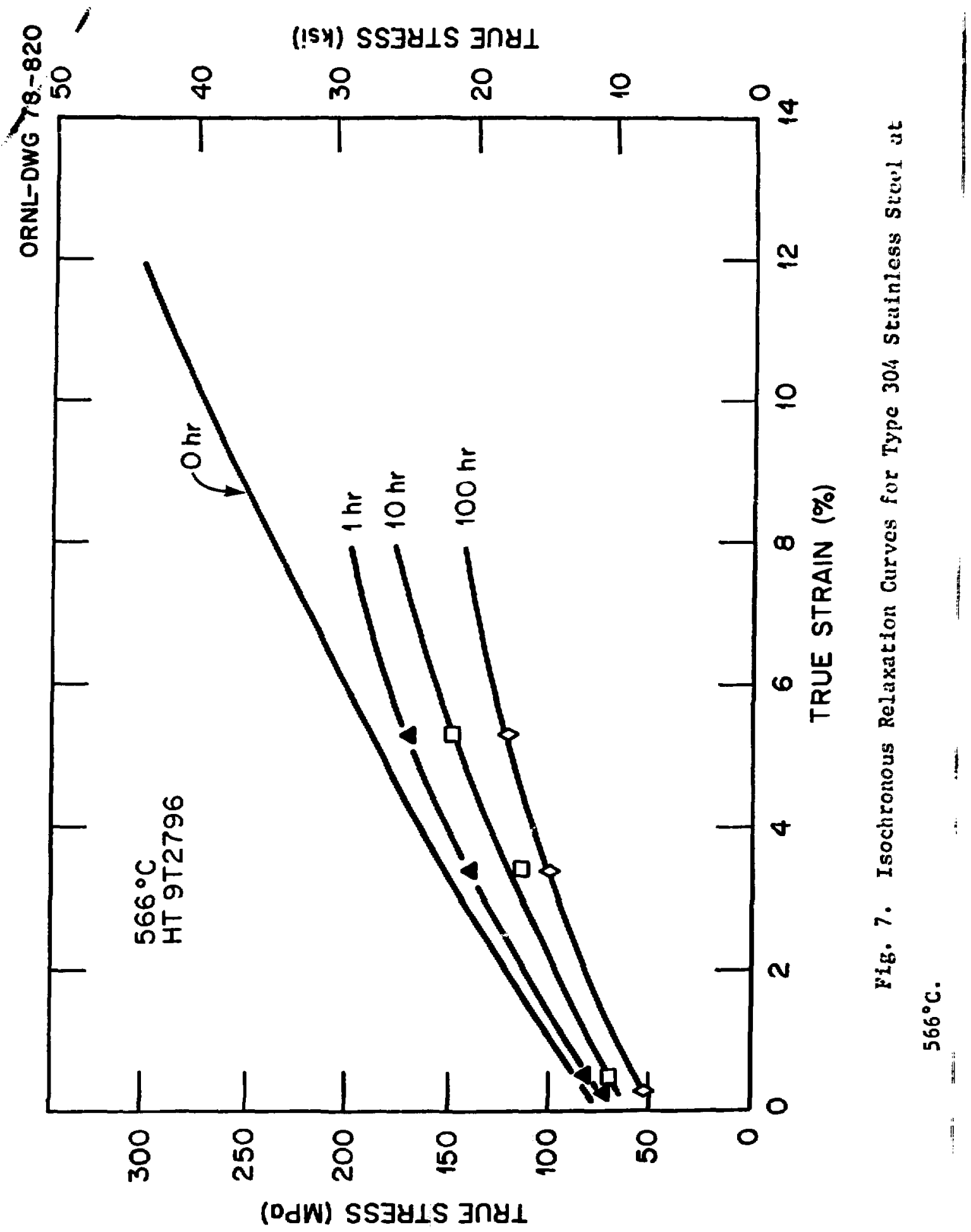




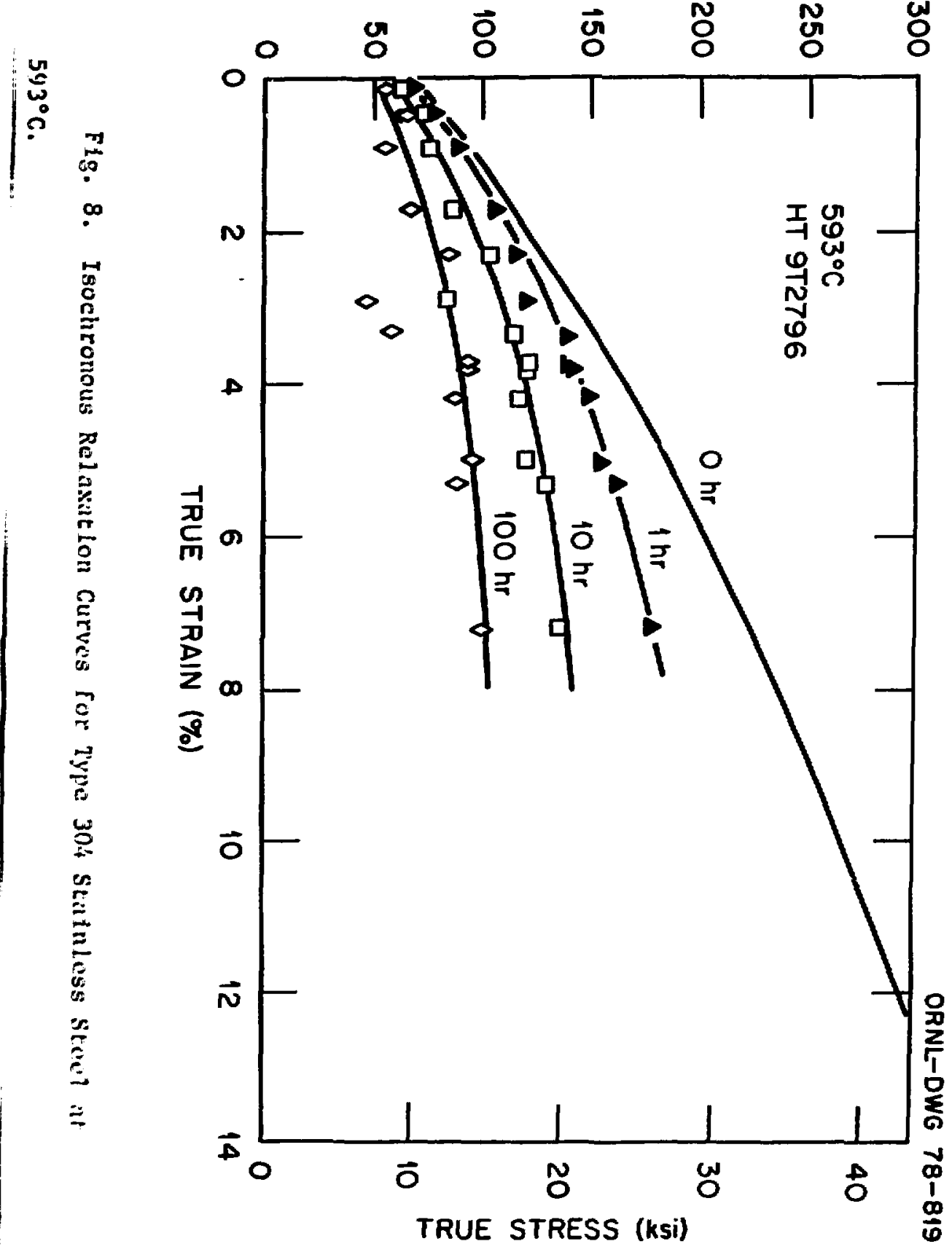


0
0
0
0

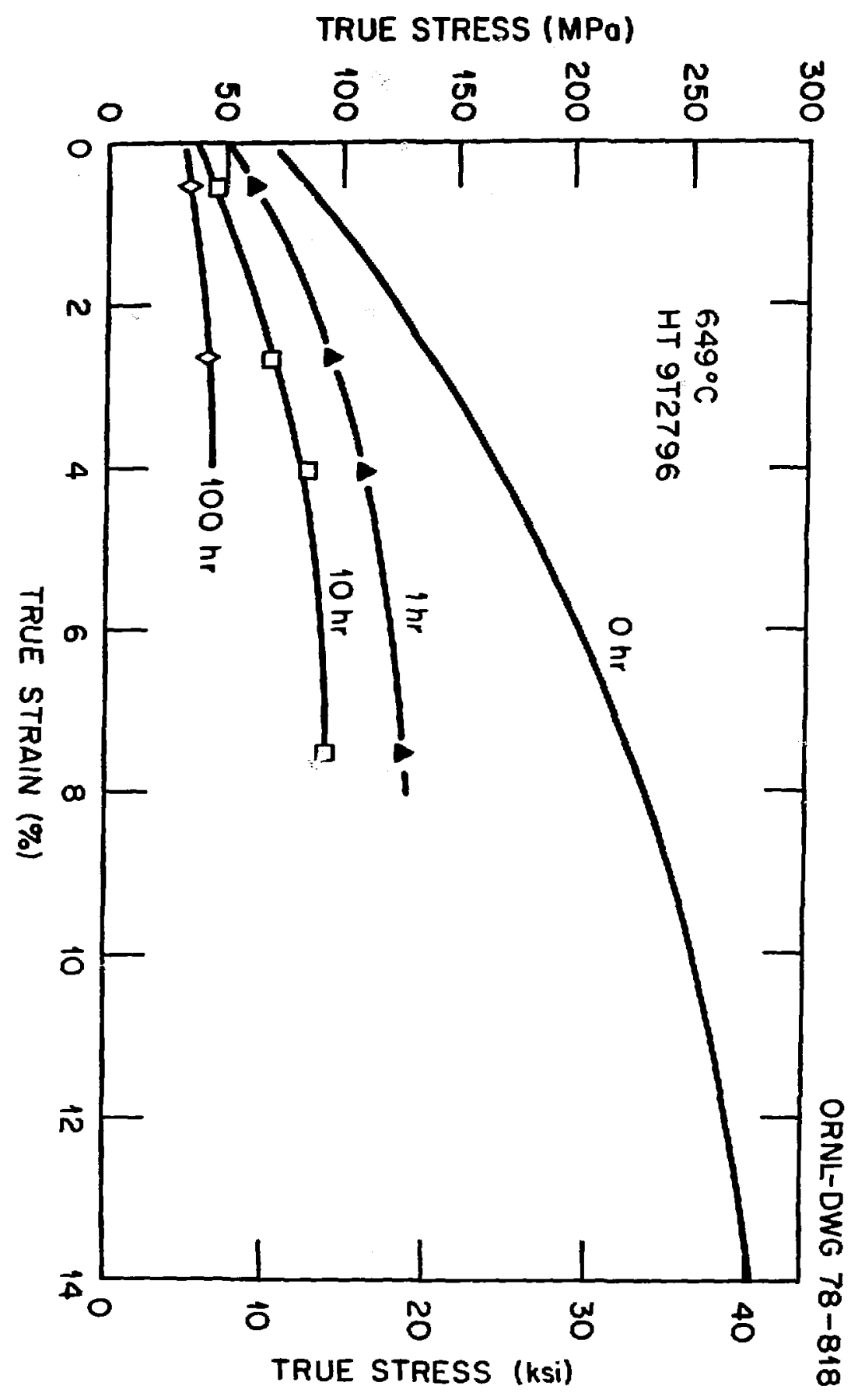




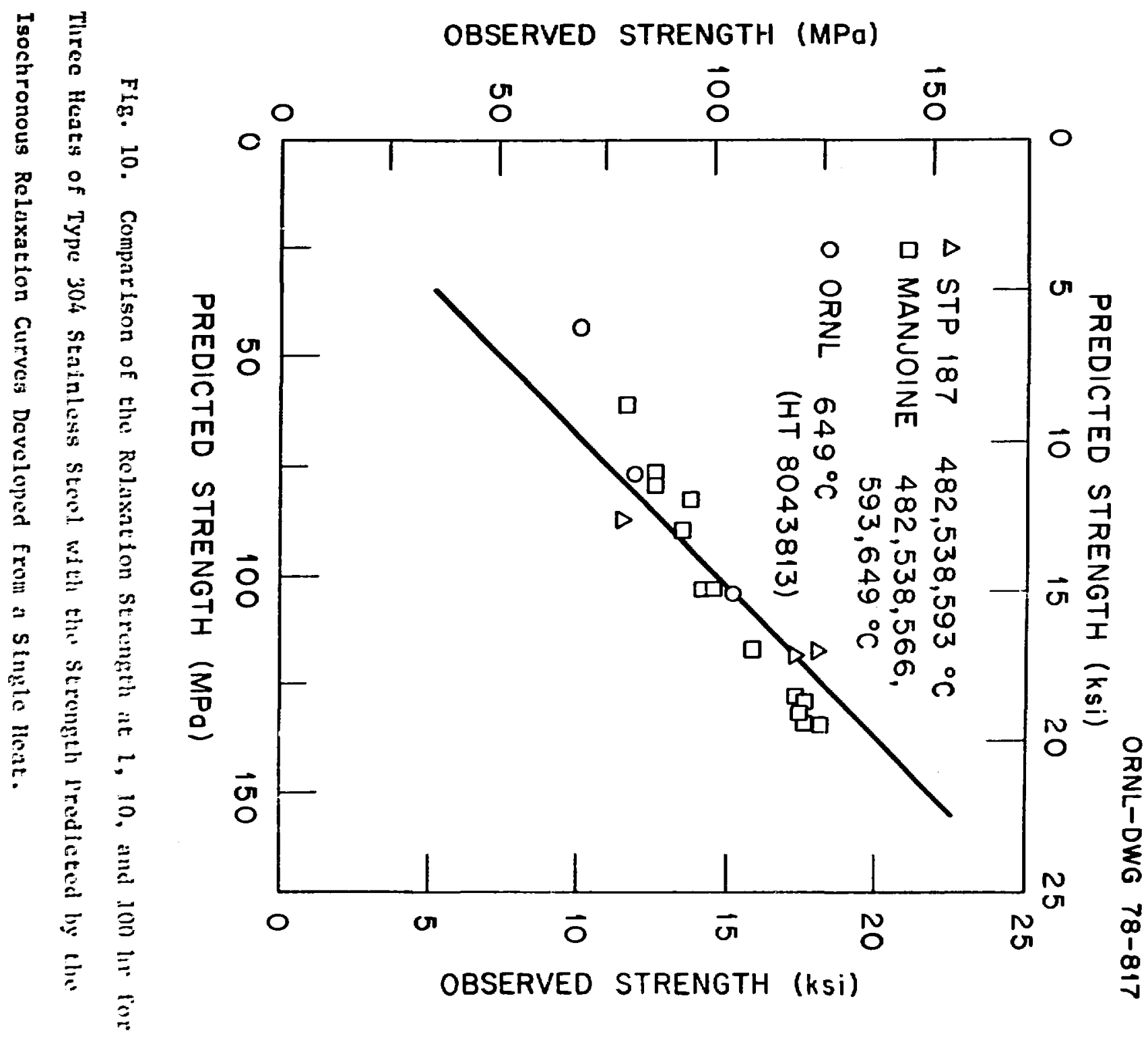


ORNL-DWG 78-815

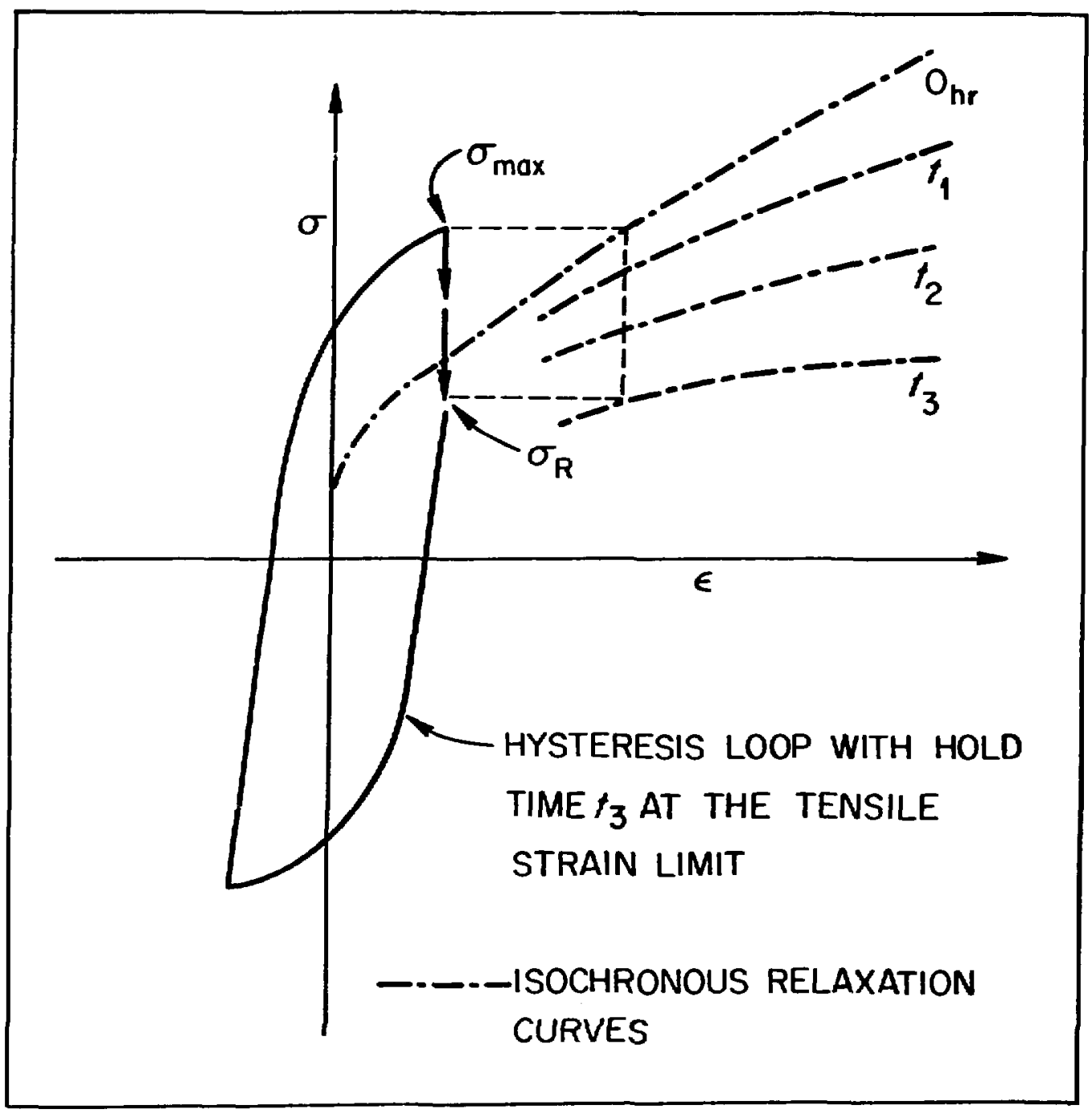

Fig. 11. Method of Estimating, the Relaxation Component of a Cyclic Test from Isochronous Relaxation Curves. Stress ( $(0)$; strain ( $)$. 


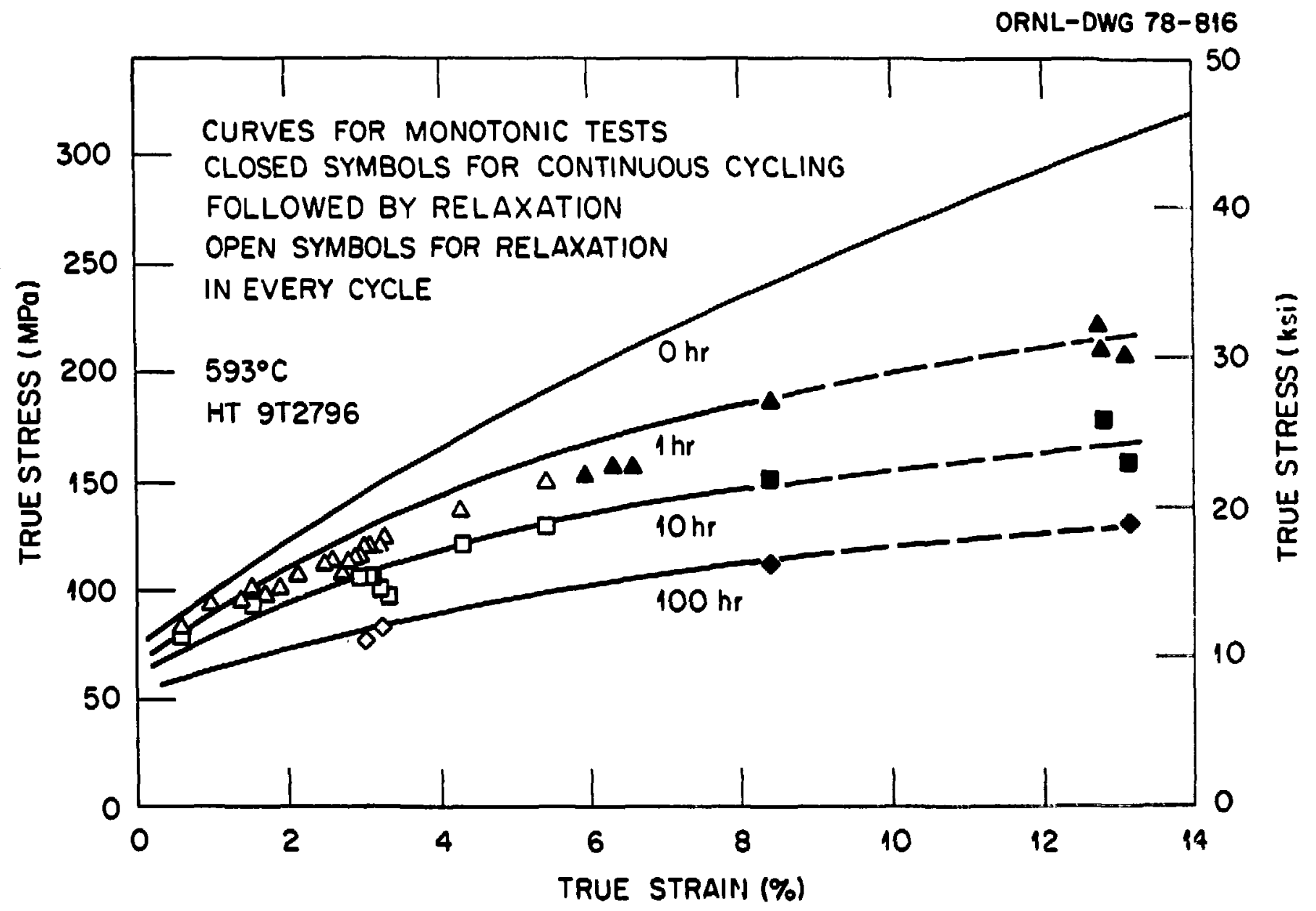

Fig. 12. Comparison of Relaxation Data from Cyclic Teste with Isodirobus Relaxation Curves Veveloped from Monotonic lests at $593^{\circ} \mathrm{C}$. Straln ramess from near $0.4 \%$ to $2.0 \%$ 


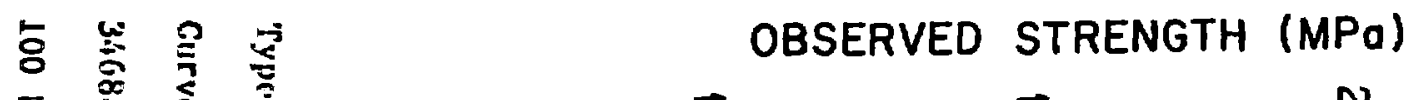

$\bar{్}$

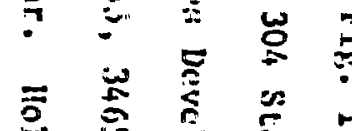

$\begin{array}{llll}\overrightarrow{5} & \overrightarrow{0} & \overrightarrow{0} & 0 \\ 0 & 0 & 0\end{array}$

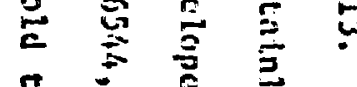

官

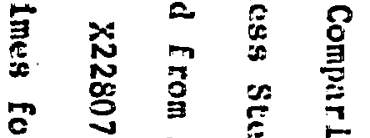

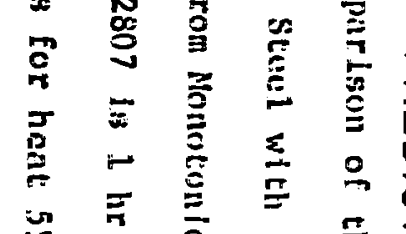

ज 5

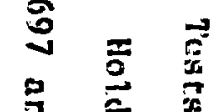

言突 离

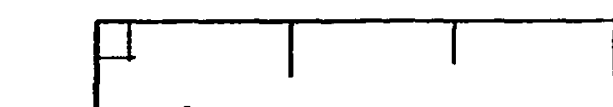

$\sim \cong$

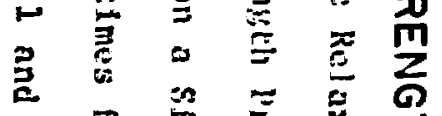

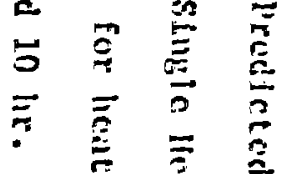

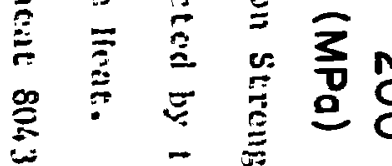

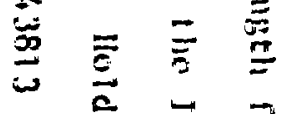

$\vec{a} \overline{0} \overrightarrow{0}$

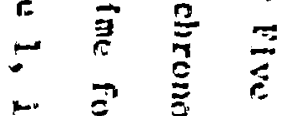

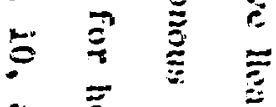

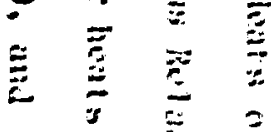

ग

응

- 0

ज

T

$-$

O

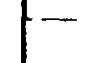




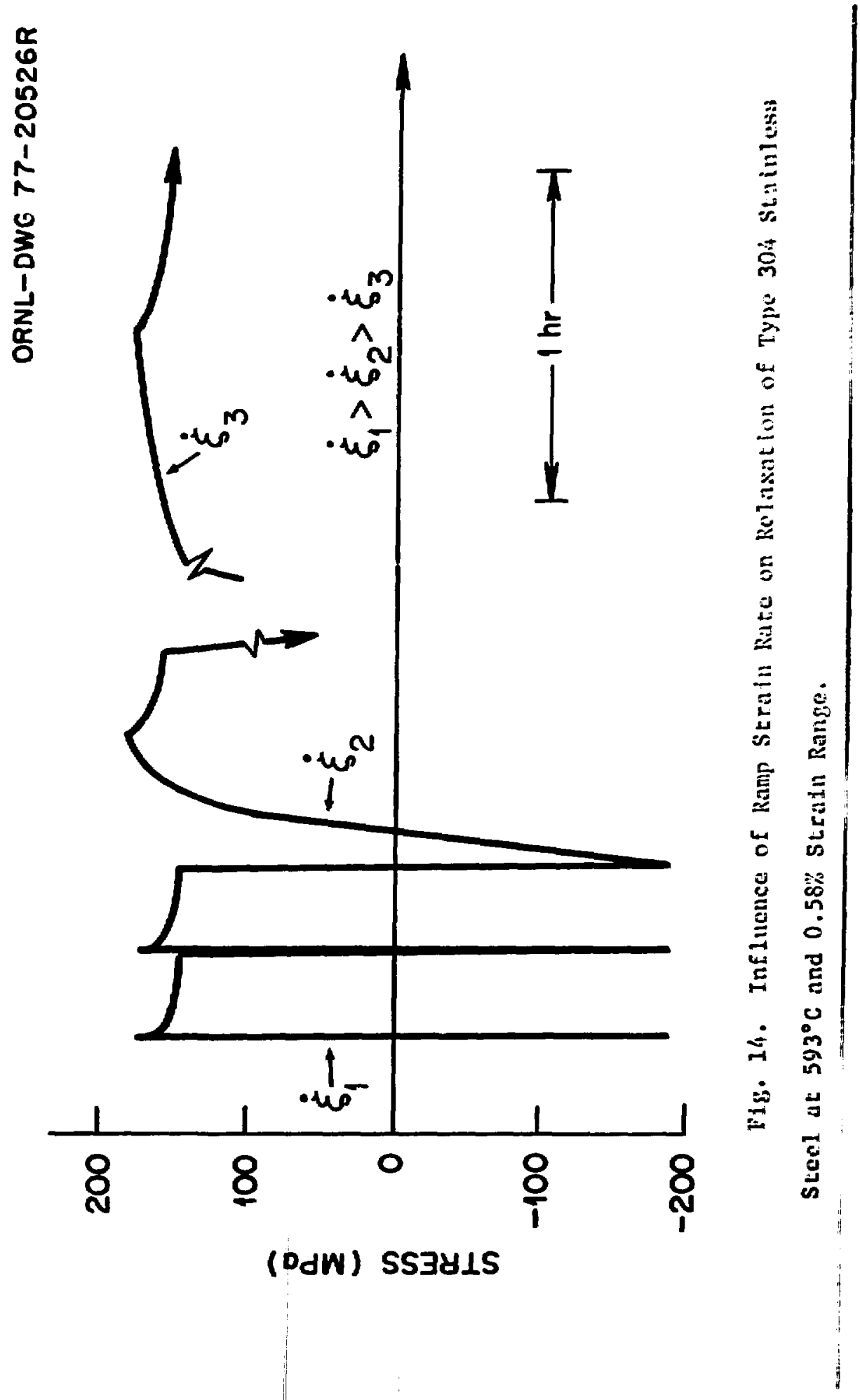




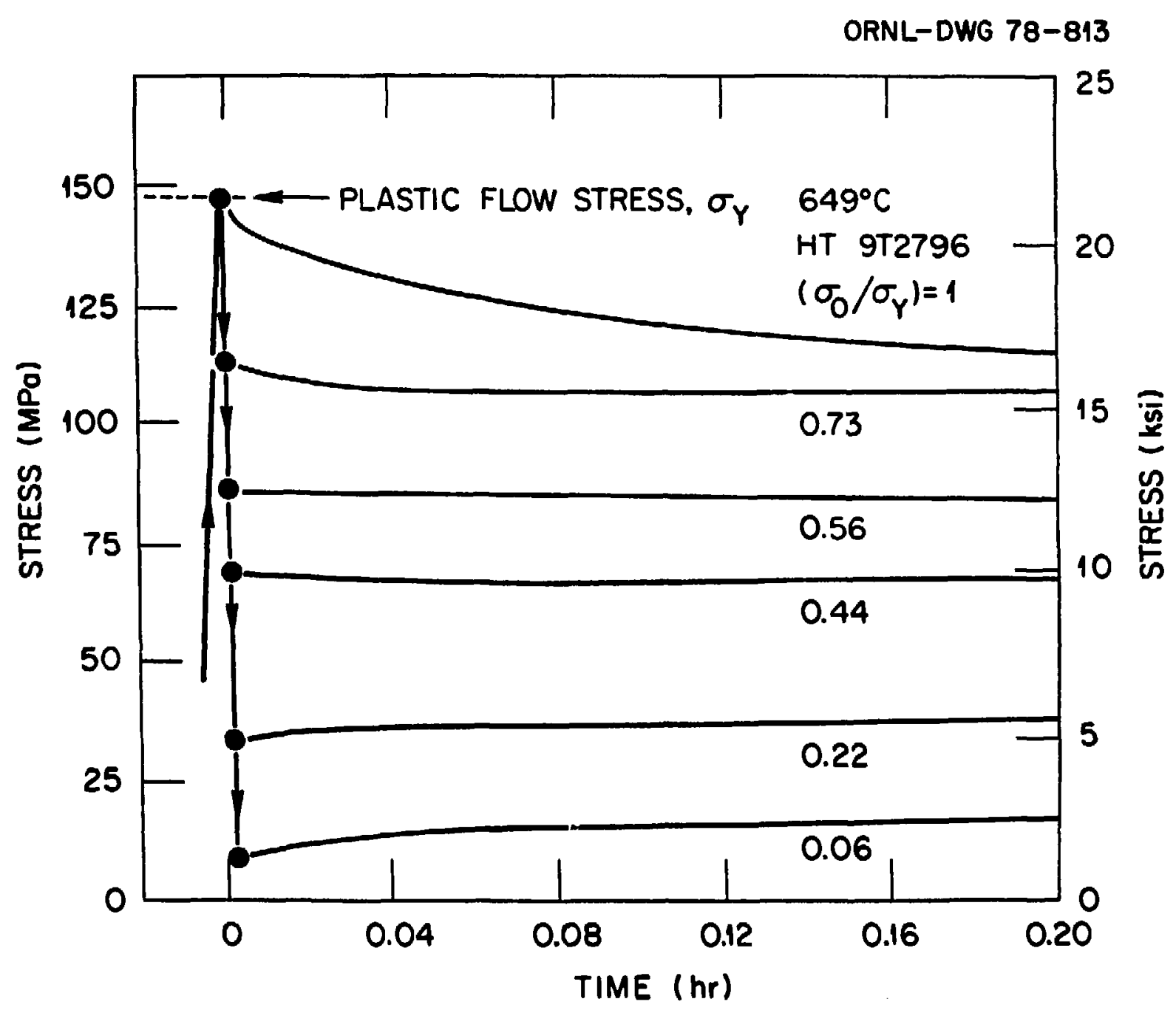

Fig. 15. Relaxation Curves produced by Rapfdly Reducing the Startius sitresti, $\sigma_{0}$, to Various Fractions of the Flow stress, $\sigma_{y}$ Type 304 stainless steel at: $649^{\circ} \mathrm{C}$. 


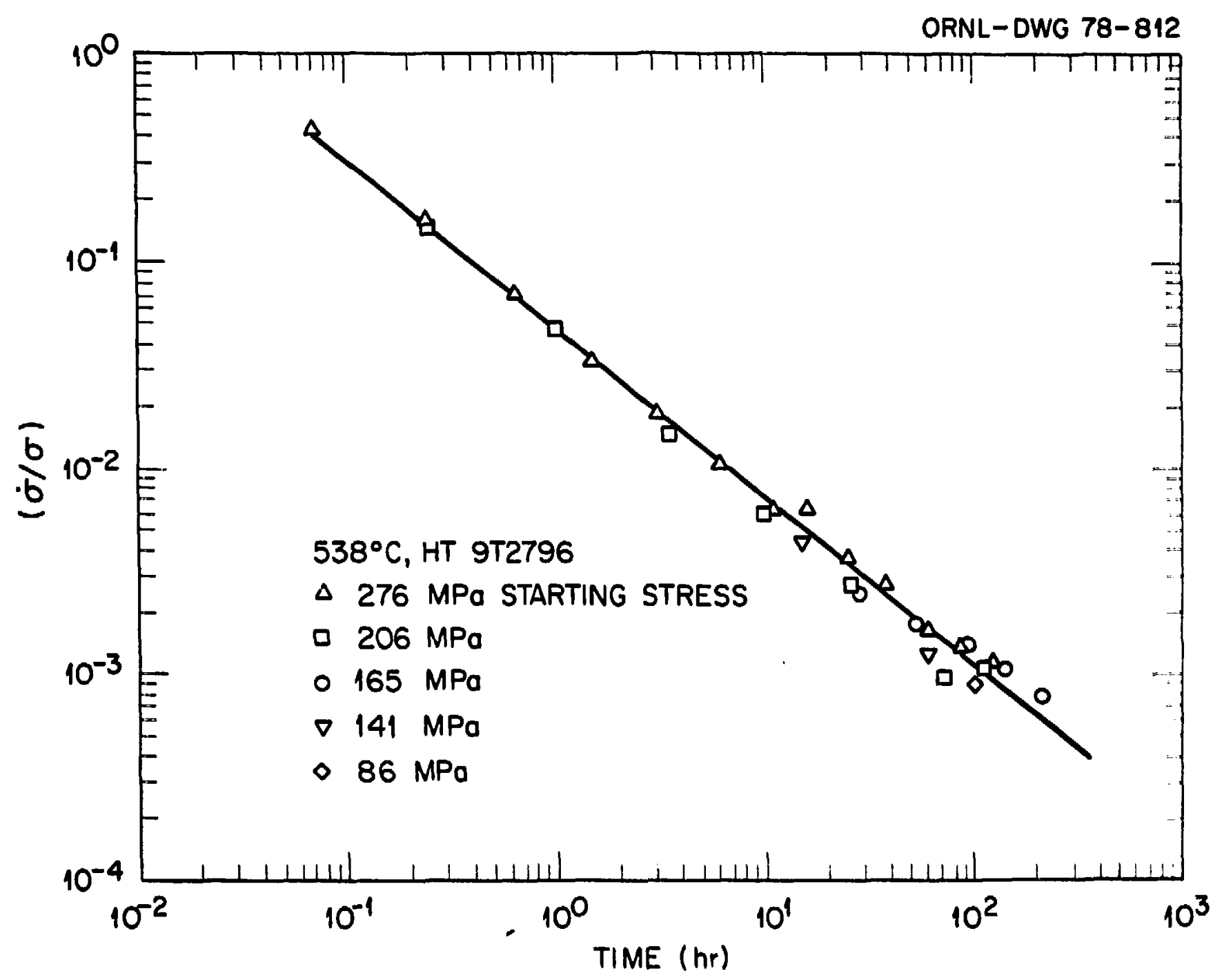

Fig. 16. Relayation Data for Type 30.4 Stainless Sted plotted by the Conwny Method. 